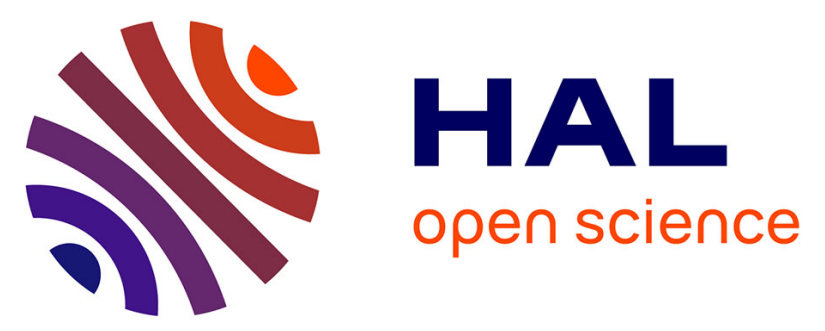

\title{
DISH STIRLING SYSTEM POTENTIAL ASSESSMENT FOR EIGHT MAIN SITES IN MADAGASCAR
}

Jean-Philippe Praene, Harimisa Radanielina, Hery Tiana Rakotondramiarana

\section{- To cite this version:}

Jean-Philippe Praene, Harimisa Radanielina, Hery Tiana Rakotondramiarana. DISH STIRLING SYSTEM POTENTIAL ASSESSMENT FOR EIGHT MAIN SITES IN MADAGASCAR. JP Journal of Heat and Mass Transfer, 2016, 13 (1), pp.119-141. 10.17654/HM013010119 hal-01175730

\author{
HAL Id: hal-01175730 \\ https://hal.science/hal-01175730
}

Submitted on $20 \mathrm{Jul} 2015$

HAL is a multi-disciplinary open access archive for the deposit and dissemination of scientific research documents, whether they are published or not. The documents may come from teaching and research institutions in France or abroad, or from public or private research centers.
L'archive ouverte pluridisciplinaire $\mathbf{H A L}$, est destinée au dépôt et à la diffusion de documents scientifiques de niveau recherche, publiés ou non, émanant des établissements d'enseignement et de recherche français ou étrangers, des laboratoires publics ou privés.

\section{(ㅇ)(1) $\$$}

Distributed under a Creative Commons Attribution - NonCommercial - NoDerivatives $\mid 4.0$ 


\title{
DISH STIRLING SYSTEM POTENTIAL ASSESSMENT FOR EIGHT MAIN SITES IN MADAGASCAR
}

\author{
Jean Philippe Praene ${ }^{a}$, Mamy Harimisa Radanielina ${ }^{\mathrm{b}}$ and Hery Tiana \\ Rakotondramiarana ${ }^{\mathrm{b}}$
}

${ }^{a}$ PIMENT Laboratory

University of Reunion Island

117 rue du Général Ailleret

97430 Le Tampon, Reunion

${ }^{\mathrm{b}}$ Institute for the Management of Energy (IME)

University of Antananarivo

BP 566, Antananarivo 101, Madagascar

\begin{abstract}
Solar energy is a green and attractive renewable energy source that can be converted for power generation. The objective of this work is to evaluate the potential of dish Stirling systems if they are used in the fourth worldwide largest island of Madagascar. For that purpose, a theoretical model of the dish Stirling system based on the geometrical configuration and heat transfer was developed and coded on Matlab. Simulations were run to investigate the energy efficiency variation of the system for eight main sites in Madagascar. As results, the proposed model enables to represent the system thermal behaviour to assess its efficiency. Among the eight studied sites, those which are on the coastal zones are more propitious to the dish Stirling system. While, in the north and northwest, the sites of Diego Suarez and Majunga present high efficiencies with, respectively, 31.65(\%) and 31.07(\%), it is in the south in fort-dauphin that thermal efficiency rate is maximal with $32.17(\%)$. Convincing results that suggest that the implementation of this kind of facility will solve a large part of energy supply problems in these regions.
\end{abstract}

Received: April 7, 2015; Accepted: June 8, 2015

Keywords and phrases: dish Stirling, engine, modelling, energy efficiency, solar energy. 


\section{Nomenclature}

$$
\begin{aligned}
& \text { A } \quad \text { : Area }\left(\mathrm{m}^{2}\right) \\
& a, b, c, d, e, r \text { : Constant coefficients } \\
& \text { c : Thermal mass capacity }\left(\mathrm{J}^{\mathrm{kg}} \mathrm{kg}^{-1} \cdot \mathrm{K}^{-1}\right) \\
& \text { C } \quad \text { : Concentration factor } \\
& c_{v} \quad: \text { Molar specific heat capacity of the working gas } \\
& \left(\mathrm{J} . \mathrm{mol}^{-1} \cdot \mathrm{K}^{-1}\right) \\
& \text { D } \quad \text { : Collector aperture diameter (m) } \\
& f \quad \text { : Focal length (m) } \\
& \text { h : Heat transfer coefficient }\left(\mathrm{W} . \mathrm{K}^{-4} \text { or W.K }{ }^{-2}\right. \text { or } \\
& \left.\mathrm{W} \cdot \mathrm{m}^{-1} \cdot \mathrm{K}^{-1}\right) \\
& \text { I : Solar radiation intercepted by the parabolic collector } \\
& \left(\mathrm{W} \cdot \mathrm{m}^{-2}\right) \\
& k_{0} \quad \text { : Conductive thermal loss coefficient (W.K }{ }^{-1} \text { ) } \\
& \text { L } \quad \text { : Backward axial distance (m) } \\
& \text { M : Mass (kg) } \\
& \text { p : Non-dimensional parameter } \\
& \text { P : Power (W) } \\
& \text { T : Temperature (K) } \\
& v \quad \text { : Wind speed }\left(\mathrm{m} . \mathrm{s}^{-1}\right)
\end{aligned}
$$




\section{Greek Symbols}

$$
\begin{aligned}
& \alpha \quad \text { : Absorption coefficient of the absorber } \\
& \varepsilon \quad \text { : Emissivity } \\
& \varepsilon_{r} \quad \text { : Effectiveness of the regenerator } \\
& \eta \quad \text { : Thermal efficiency } \\
& \sigma_{\text {align }}: \text { Absorber alignment over the focal point (rad) } \\
& \sigma_{d} \quad \text { : Tracking (drive) (rad) } \\
& \sigma_{\text {incl }} \quad \text { : Slope of the structure (rad) } \\
& \sigma_{r e f}: \text { Mirror reflectivity (rad) } \\
& \sigma_{s} \quad \text { : Tracking (sensor) (rad) } \\
& \sigma_{\text {sol }} \text { : Sun's width (rad) } \\
& \sigma_{\text {tot }} \quad \text { : Total error of the system (rad) } \\
& \Phi_{c v, a h}: \text { Convective flux due to wind }\left(\mathrm{W} . \mathrm{m}^{-2}\right) \\
& \Phi_{c v, h e} \text { : Convective flux between heating source and working fluid } \\
& \text { into the expansion chamber of Stirling engine }\left(\mathrm{W} . \mathrm{m}^{-2}\right) \\
& \Phi_{c v, k c} \text { : Convective flux due to cooling source into the compression } \\
& \text { chamber of Stirling engine }\left(\mathrm{W} . \mathrm{m}^{-2}\right) \\
& \varphi_{\text {in }} \quad \text { : Intercepted factor } \\
& \Phi_{r d, c h} \text { : Radiative flux between the parabolic collector and the } \\
& \text { heating source }\left(\mathrm{W} \cdot \mathrm{m}^{-2}\right) \\
& \Phi_{r d, \text { sol }} \text { : Radiative flux from solar radiation }\left(\mathrm{W} . \mathrm{m}^{-2}\right)
\end{aligned}
$$




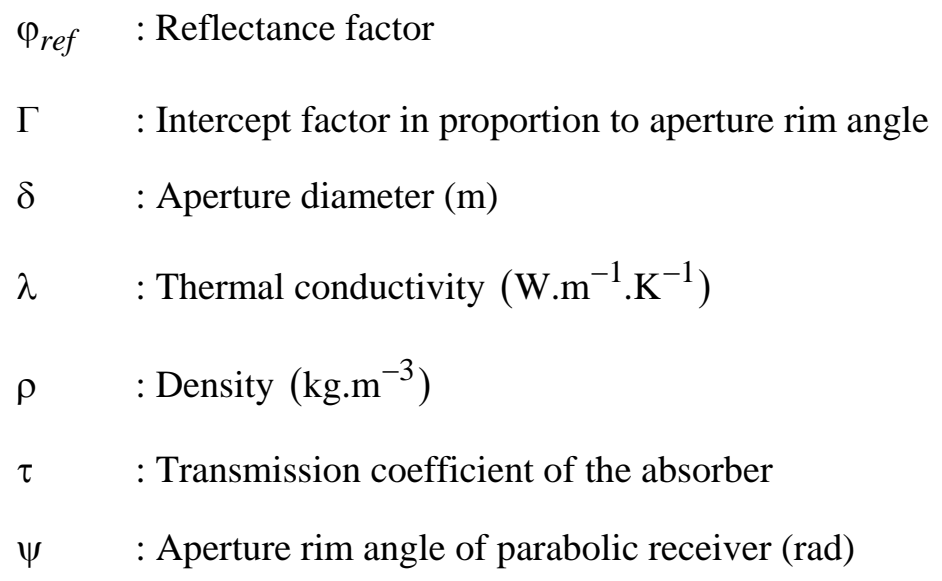

\section{Subscripts}

$\begin{array}{ll}\text { abs } & : \text { Absorber } \\ \text { align } & : \text { Absorber alignment } \\ c d & : \text { Conduction } \\ \text { comp } & : \text { Compression chamber } \\ c v & : \text { Convection } \\ \text { dir } & : \text { Direct } \\ \text { exp } & : \text { Expansion chamber } \\ \text { ext } & : \text { outside } \\ h & : \text { Heating source } \\ \text { in } & : \text { Intercepted } \\ k & : \text { Cooling source } \\ p c & : \text { Parabolic collector } \\ r & : \text { Regenerator } \\ r d & : \text { Radiation } \\ r e f & : \text { Reflectance }\end{array}$




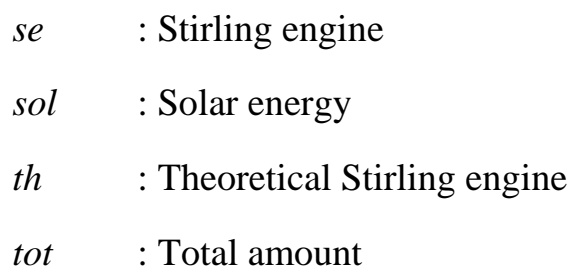

\section{Introduction}

To cope with the threat of climate change and the depletion of fossil fuel resources, solar energy conversion is one of the alternative solutions to the use of natural fossil energy resources for power generation. More accurately, such conversion can be done with whether direct or indirect approach. While the direct approach consists in converting solar energy into electricity directly by means of photovoltaic systems; the indirect approach, upon which is based any solar thermal power system functioning, consists in converting solar radiation by use of a solar concentrator system into thermal energy and then into electricity. In fact, there are three sorts of solar concentrator systems [1], namely: through or line-focus systems, power towers using suntracking heliostats, and dish engine systems in which can be classified the dish Stirling system that constitutes the subject of this paper. Madagascar has a huge potential in renewable energy deployment, [2-4] however, the investigation are few on the different regions of the island of Madagascar.

While the invention of Stirling engine due to Stirling [5], it was Ericsson who succeeded in adapting Stirling engine to work with solar energy in 1870. Several research works have been carried out since then and it is reported by many works that solar powered dish Stirling engine can now have high efficiency like 30(\%); readers interested on the development of solarpowered Stirling engines can refer to Kongtragool and Wongwises [6]. The study of solar concentrating system has been widely investigated both on energy or exergy aspects, [7-9]. Most of the time dish Stirling system are developed for electrical loads, in recent case this system has been coupled with conventional HVAC system in order to produce hot water or heating for buildings [10]. In the last 20 years, many systems has been commercialized in a range power of 2 to $50(\mathrm{~kW})[11]$. 
Madagascar is the fourth largest island in the world and is located in the Indian Ocean off the eastern coast of Southern Africa, in the east of Mozambique. It has a total area of 587,041 square kilometres and has about 20,005,222 of inhabitants. Referring to MEM $^{1}$ surveys [12], the energy mix in Madagascar is strongly dominated by fuel wood that represents 92(\%) of the energy supply as shown in Figure 1 . The share of renewable energy is only less than $1(\%)$ of which hydropower is the most exploited renewable energy source and represents 54(\%) of power generation in Madagascar.

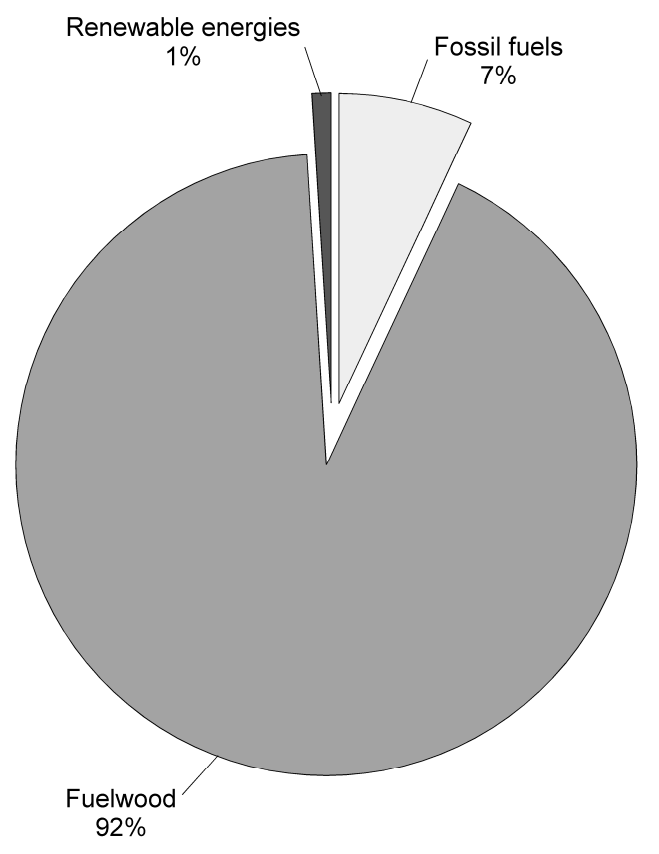

Figure 1. Power generation share based on the installed power.

Furthermore, according to surveys done by $\mathrm{ADER}^{2}$, while urban power generation is almost monopolized by a state-managed company, rural electricity production is mainly ensured by private power utility companies and regards especially hydropower generation and the part of solar power

\footnotetext{
${ }^{1}$ Mines and Energy Ministry or "Ministère de l'Energie et des Mines"

${ }^{2}$ Malagasy Agency of Rural Electrification Development or “Agence pour le Développement de l'Electrification Rurale”
} 
plants is less than $0.01(\%)$ [13]. Hence, other options including solar energy technologies are considered by the Malagasy government for power generation in rural and remote areas notably. Indeed, while its rich endemic species biodiversity being threaten by continuous deforestation due to bush fire, firewood collection and charcoal production, this island has a significant solar potential of about 2,000( $\left.\mathrm{kWh} . \mathrm{m}^{-2}\right)$ annually, that is, an intercepted solar radiation power of $750\left(\mathrm{~W} . \mathrm{m}^{-2}\right)$ for $2,800(\mathrm{~h})$ of daylight time and it can reach more than 5,500 $\left(\mathrm{W} \cdot \mathrm{m}^{-2}\right)$ in the North and South regions of the island. As such solar potential is still underexploited; the present investigation focuses on the assessment of the potential of dish Stirling in a certain number of Madagascar regions.

\section{System Description and Methodology}

\subsection{System description}

A dish Stirling system comprises a parabolic dish concentrator, a thermal receiver and a Stirling engine positioned at the focus of the dish [1]; the whole being mounted on a structure that tracks the sun by pivoting on one or two axes [14].

As shown in Figure 2, a Stirling engine cycle operates on a closed regenerative thermodynamic cycle using a working gas which is subjected to expansion and compression processes at different temperatures [15]. This working gas is warmed up in heating chamber and a cooling system enables to cool the gas, which is reintroduced by a regenerator halfway between the two systems.

Parabolic dish dimensions depend on the aperture size that not only influences the intercepted solar radiation, but also increases convection and radiation heat losses on the absorber [16]. Isolation walls are supposed to surround the absorber and the heat transfer in to it is assumed to be only by conduction process. 


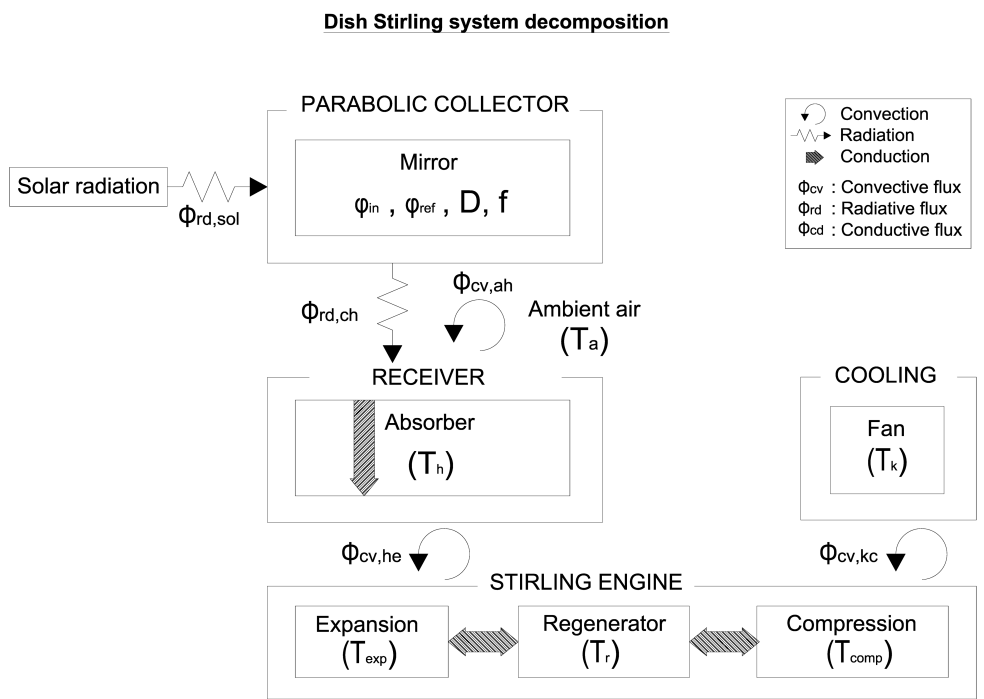

Figure 2. Dish Stirling system decomposition.

\subsection{System modelling}

\subsubsection{Parabolic collector}

The concentration ratio between parabolic receiver and absorber sizes strongly depends on the collector rim angle which is an indicator of its curvature [14]. So, the collector projected area $A_{p c}$ is determined by:

$$
A_{p c}=4 \pi\left(f \sin (\psi)(1+\cos (\psi))^{-1}\right)^{2}
$$

where $\psi$ and $f$ are, respectively, the aperture rim angle of parabolic receiver (rad) and the focal length (m), and commonly determined with the following relationship:

$$
\psi=\arctan \left(\frac{p(1+\cos (\psi))}{2 D}\left(2\left(\frac{f}{D}\right)^{2}-\frac{1}{8}\right)^{-1}\right),
$$

where $p$ is a non-dimensional parameter and $D$ is the collector aperture diameter (m). 


\subsubsection{Absorber}

\subsubsection{Intercepted power}

The intercept factor, that is the fraction of solar radiation reflected by the collector and intercepted by the absorber on the focal point, is influenced by collector and absorber aperture sizes. For the absorber, the aperture diameter $\delta(m)$ is written:

$$
\delta=D L\left(f\left(1-\left(\frac{D}{4 f}\right)^{2}\right) \cos 2(\psi)\right)^{-1},
$$

where $L$ the backward axial distance (m) from the absorber aperture to the focal point.

The typical errors of the system are supposed due to geometrical configuration: slope of the structure $\sigma_{i n c l}$, tracking $\sigma_{s}$ (sensor) and $\sigma_{d}$ (drive), absorber alignment $\sigma_{\text {align }}$ over the focal point, mirror reflectivity $\sigma_{r e f}$, sun's width $\sigma_{\text {sol }}$ [14]. These errors influence the solar radiation input and the system efficiency. The total error of the system $\sigma_{\text {tot }}$ can be determined by:

$$
\sigma_{\text {tot }}=\left(\left(2 \sigma_{\text {incl }}\right)^{2}+\sigma_{s}^{2}+\sigma_{d}^{2}+\sigma_{\text {align }}^{2}+\left(2 \sigma_{\text {ref }}\right)^{2}+\sigma_{\text {sol }}^{2}\right)^{0.5} \text {. }
$$

The intercepted power by the absorber $P_{\text {in }}\left(\mathrm{W} \cdot \mathrm{m}^{-2}\right)$ can be expressed in terms of the incident solar radiation intercepted by the parabolic collector $I_{\text {dir }}\left(\mathrm{W} . \mathrm{m}^{-2}\right)$, the intercept factor $\varphi_{i n}$ and the reflectance factor $\varphi_{\text {ref }}$ as follows:

$$
P_{i n}=I_{d i r} A_{p c} \varphi_{i n} \varphi_{r e f}
$$

such that $\varphi_{\text {ref }}$ depends on the collector mirror reflectance ratio and fluctuates between 91 and 97\%, whereas $\varphi_{\text {in }}$ is computed by:

$$
\varphi_{\text {in }}=\frac{1}{I_{d i r} A_{c}} \sum_{\psi=0^{\circ}}^{\psi_{\text {tot }}} \Gamma 8 \pi I_{d i r} f^{2} \sin (\psi)\left((1+\cos (\psi))^{2}\right)^{-1} \Delta \psi
$$


in which $\Gamma$ denotes the intercept factor in proportion to aperture rim angle and is given as follows:

$$
\begin{aligned}
& \Gamma=1-2 Q(x) ; Q(x)=g(x)\left(a t+b t^{2}+c t^{3}+d t^{4}+e t^{5}\right) ; \\
& x=\sigma_{\text {tot }}^{-1} \tan ^{-1}\left(\frac{\delta \cos (\psi)}{2 p}\right) ; g(x)=\frac{e^{-\frac{x^{2}}{2}}}{\sqrt{2 \pi}} ; t=\frac{1}{1+r x},
\end{aligned}
$$

where $\delta$ and $\sigma_{\text {tot }}$ are calculated by equations (3) and (4), respectively, while $a, b, c, d, e$ and $r$ denote constant coefficients.

\subsubsection{Absorber temperature}

The thermal balance equation onto the upper area of the absorber can be written as:

$$
M_{a b s} c_{a b s} \frac{d T_{a b s}}{d t}=h_{r d-c v, e x t} A_{a b s}\left(T_{a}-T_{a b s}\right)+A_{a b s} P_{i n},
$$

where $M_{a b s}, c_{a b s}$ and $A_{a b s}$ are, respectively, the mass (kg), specific heat $\left(J . \mathrm{Kg}^{-1} \cdot \mathrm{K}^{-1}\right)$ and aperture area $\left(\mathrm{m}^{2}\right)$ of the absorber, $T_{a}$ and $T_{a b s}$, ambient air and absorber temperatures (K). The heat transfer coefficient $h_{r d-c v, \text { ext }}$ is obtained by combining convective and radiative coefficients as follows:

$$
h_{r d-c v, e x t}=h_{r d, e x t}+h_{c v, e x t},
$$

where $h_{r d \text {, ext }}$ depends on the wind speed $v\left(m . s^{-1}\right)$, and $h_{c v}$, ext is subject to the absorber and ambient air temperatures and the emissivity of the absorber $\varepsilon_{a b s}$, these coefficients are given by:

$$
\begin{aligned}
& h_{r d, \text { ext }}=\varepsilon_{a b s} \sigma\left(T_{a}^{4}-T_{a b s}^{4}\right), \\
& h_{c v, \text { ext }}=3.9 v+5.62,
\end{aligned}
$$

where $\sigma$ is the Stefan-Boltzmann constant $\left(\mathrm{W} \cdot \mathrm{m}^{-2} \cdot \mathrm{K}^{-4}\right)$. 


\subsubsection{Dish Stirling efficiency}

The theoretical Stirling engine efficiency $\eta_{t h}$ is determined according to the efficiency of parabolic collector $\eta_{p c}$, and that of Stirling engine $\eta_{s e}$ [16-18] as follows:

$$
\eta_{t h}=\eta_{p c} \eta_{d e}
$$

The thermodynamic modelling of the dish Stirling system has to consider conduction, convection and radiation losses. Hence, thermal efficiency of the parabolic collector $\eta_{p c}$ is obtained by:

$$
\eta_{p c}=\eta_{0}-\frac{1}{I_{d i r} C}\left[h\left(T_{h}-T_{a}\right)+\varepsilon_{a b s} \sigma\left(T_{h}^{4}-T_{a}^{4}\right)\right],
$$

where $T_{h}$ and $T_{a}$, respectively refer to the heating source (absorber) and ambient air temperatures (K), $h$ represents the convection and radiative heat transfer coefficient of the Stirling engine $\left(\mathrm{W} . \mathrm{m}^{-2} \cdot \mathrm{K}^{-1}\right) ; I_{d i r}, \varepsilon_{a b s}$ and $\sigma$, respectively, denote the direct solar flux intensity $\left(\mathrm{W} . \mathrm{m}^{-2}\right)$, the emissivity of the absorber and Stefan-Boltzmann constant $\left(\mathrm{W} \cdot \mathrm{m}^{-2} \cdot \mathrm{K}^{-4}\right)$; $\eta_{0}$ represents the parabolic collector optical efficiency and given by:

$$
\eta_{0}=\tau \alpha \varphi_{r e f},
$$

where $\tau$ and $\alpha$, respectively, denote the absorber transmission and absorption coefficients.

The above mentioned concentration factor $C$ of the system in equation (12) is the ratio between the parabolic collector and absorber areas (respectively, $A_{p c}$ and $A_{a b s}$ ) is obtained by:

$$
C=\frac{A_{p c}}{A_{a b s}} .
$$

Basing on cyclic period of the Stirling engine, thermal efficiency of the engine $\eta_{s e}[17,18]$ is given as follows: 


$$
\begin{aligned}
\eta_{s e}= & \frac{T_{1}-T_{2}}{T_{1}+M\left(T_{1}-T_{2}\right)} \\
& +\left(\left(k_{0}\left(T_{h}-T_{k}\right)\right)\left(\frac{T_{1}+M\left(T_{1}-T_{2}\right)}{h_{c v, h}\left(T_{h}-T_{1}\right)+h_{r d, h}\left(T_{h}^{4}-T_{1}^{4}\right)}+\frac{T_{2}+M\left(T_{1}-T_{2}\right)}{h_{c v, k}\left(T_{2}-T_{k}\right)}+F_{1}\left(T_{1}-T_{2}\right)\right)\right)
\end{aligned}
$$

where $T_{1}$ and $T_{2}$, respectively, denote the highest and lowest temperatures $(\mathrm{K})$ of the working gas into Stirling engine at isothermal processes with $T_{1}>T_{2} ; T_{h}$ and $T_{k}$ are, respectively, the temperatures of heating and cooling sources; $h_{c v, h}$ and $h_{r d, h}$ characterize convection $\left(\mathrm{W} . \mathrm{K}^{-1}\right)$ and radiative $\left(\mathrm{W} . \mathrm{K}^{-4}\right)$ heat transfer coefficients on the hot heat exchanger, $h_{c v, k}$ is the convective heat transfer coefficient $\left(\mathrm{W} \cdot \mathrm{K}^{-1}\right)$ on the cold side heat exchanger of the engine and $k_{0}$ represents the conductive thermal loss coefficient $\left(\mathrm{W} . \mathrm{K}^{-1}\right.$ ) corresponding to the heat leakage from the heat source and the heat sink; $M$ is a proportionality constant that is independent from the temperature difference but depends on the used material properties for the regenerative processes and given by:

$$
M=\frac{c_{V}\left(1-\varepsilon_{r}\right)}{R \log (\lambda)},
$$

where $c_{V}$ and $R$ are, respectively, the molar specific heat of the working gas $\left(\mathrm{J} . \mathrm{mol}^{-1} \cdot \mathrm{K}^{-1}\right.$ ) and the universal gas constant, $\lambda$ and $\varepsilon_{r}$, respectively, denote the ratio of volumes and the effectiveness of the regenerator.

The above mentioned term $F_{1}$ in equation (15) is calculated by:

$$
F_{1}=\frac{1}{n R \log (\lambda)}\left(\frac{1}{M_{1}}+\frac{1}{M_{2}}\right)
$$

where $n$ is the molar mass of the working gas $\left(g . \mathrm{mol}^{-1}\right)$, the term $\frac{1}{M_{1}}+\frac{1}{M_{2}}\left(s . K^{-1}\right)$ depends on the time of regenerative processes and the 
temperature difference between the highest and lowest temperatures $T_{1}$ and $T_{2}$ of the working gas into the engine.

\section{Results and Discussion}

\subsection{Weather data}

According to available weather database, the weather data used for simulation relate to a series of 365 days, from January 1st to December 31st, 2007, implanted in eight sites of Madagascar. Figure 3 shows the geographical location of these sites.

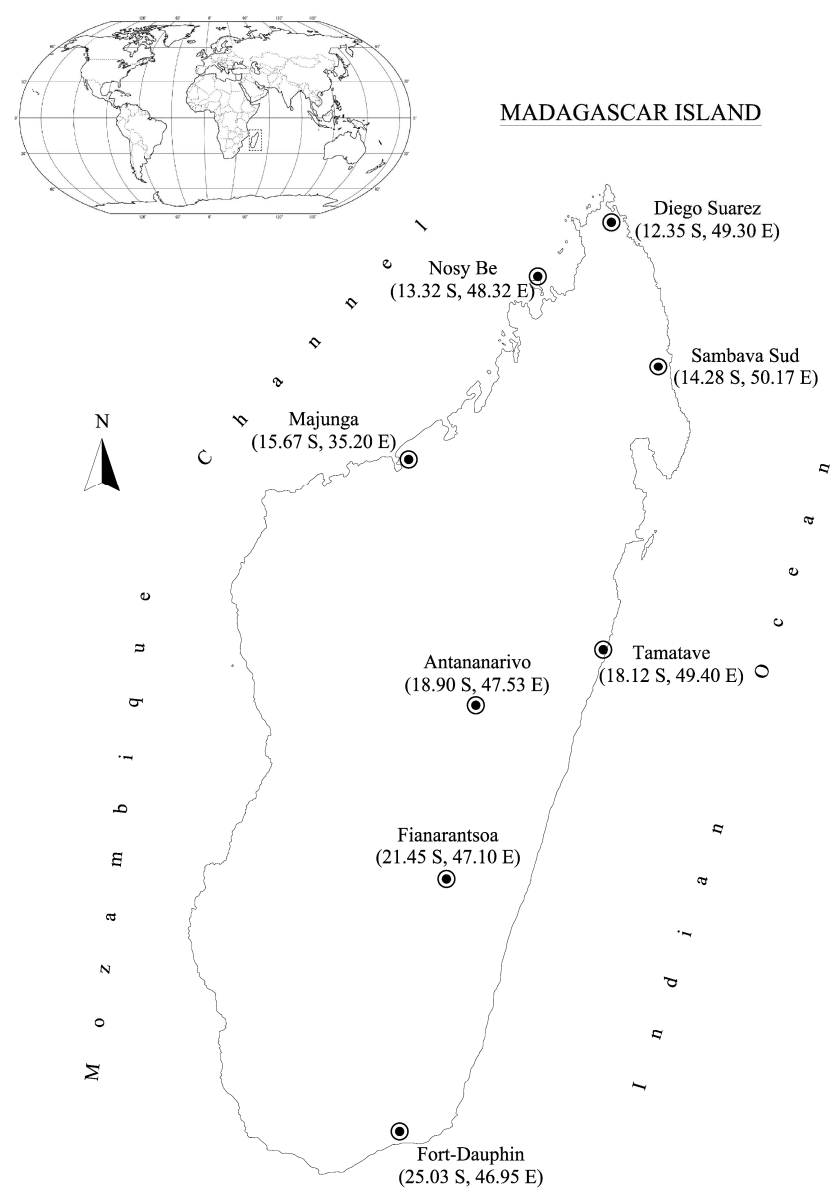

Figure 3. Geographical location of the eight studied sites in Madagascar. 
As shown in Figure 3, while six of the eight studied sites in Madagascar are located on coastal zones with altitudes $z$ under to $110(\mathrm{~m})$ : Diego Suarez $(z=105(\mathrm{~m}))$, Nosy Be $(z=9(\mathrm{~m}))$, Majunga $(z=18(\mathrm{~m}))$, SambavaSud $(z=5(\mathrm{~m}))$, Tamatave $(z=6(\mathrm{~m}))$ and Fort-dauphin $(z=9(\mathrm{~m}))$, the two other sites are situated on the central highlands with Antananarivo $(z=1300(m))$ and Fianarantsoa $(z=1109(m))$.

While the daily maximum solar radiation in Madagascar is about 750 $\left(\mathrm{W} . \mathrm{m}^{-2}\right)$, the average annual solar radiation is around $250\left(\mathrm{~W} \cdot \mathrm{m}^{-2}\right.$ ). Figure 4 shows average annual solar radiation distribution on the territory over twenty years (1986-2004) [19].

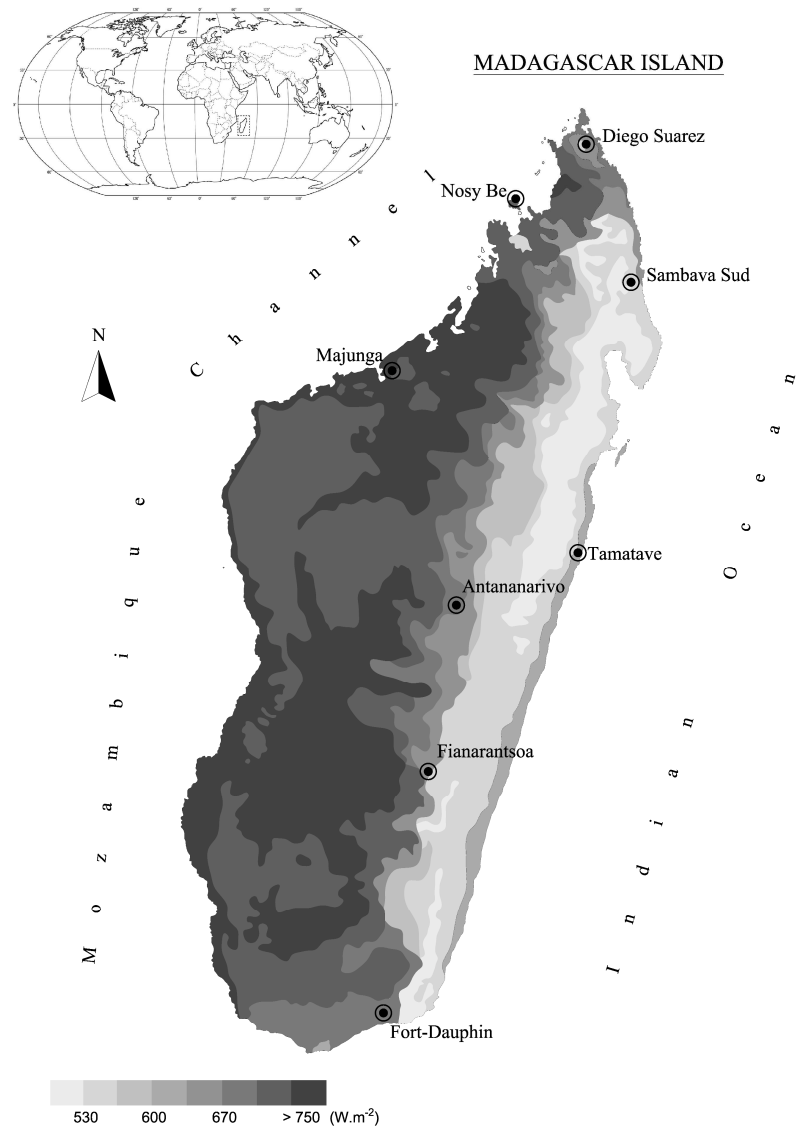

Figure 4. Yearly mean of daily solar radiation. 
Indeed, as shown in Figure 4, Madagascar has a huge solar potential on a large part of the west coast region extending from north (Diego Suarez) to south (Fort-dauphin) and on littoral zone in the east region of the island. Hence, based on weather data, the average annual solar radiation of the eight sites studied is obtained by Figure 5 .

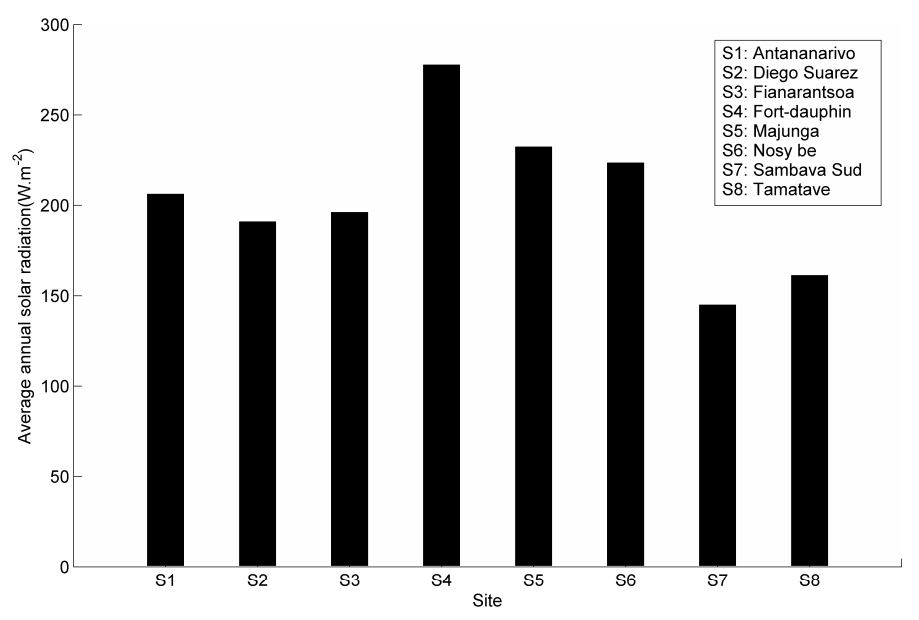

Figure 5. Average annual direct solar radiation per site.

Figure 5 obviously reveals the solar radiation distribution as above mentioned in Figure 4. Indeed, according to the weather data, the two sites on the east coast only receive around $150\left(\mathrm{~W} . \mathrm{m}^{-2}\right)$ namely Tamatave and Samabava Sud. Meanwhile, the site of Fort-dauphin (South) is submitted to a semiarid climate where the ambient temperature can reach over $40\left({ }^{\circ} \mathrm{C}\right)$, and those of Majunga (west) and Nosy be (north western) enjoy a better equatorial climate with the monsoon wind. Nevertheless, these sites have heaviest solar potential with an average solar radiation more than 200 $\left(\mathrm{W} \cdot \mathrm{m}^{-2}\right)$. Although the other sites, like Antananarivo (the capital city of Madagascar) and Fianaratsoa in the central highlands, reach this average, this highly depends on geographical position of the site and weather conditions (moisture, wind speed) that may significantly vary for the selected year for studying. 


\subsection{Dish Stirling system behaviour on the studied sites}

In this section, the main objectives are to assess the parabolic collector and Stirling engine system behaviours for the eight selected sites and to highlight the energy efficiency of this system from numerical simulations.

\subsubsection{Variation of the intercepted power by the parabolic collector and absorber temperature}

As aforesaid the system has two parts namely, on the one hand the parabolic collector, on the other hand the absorber (heating source) connected to the Stirling engine. Thereby, it is initially important to see the variation of the intercepted power of the collector that influences the absorber temperature. Henceforth, it should be noted that the collector and absorber parameters are fixed: for the collector (3-meter-diameter) and for the absorber (10-centimeter-length and 2.5-centimetrer-diameter).

While using equation (5) and taking into account the direct incident solar radiation, the collector and absorber physical parameters (length, diameter, aperture rim angle), Figure 6 shows the average intercepted power by the collector that varies between 1250 and 1950(W) a year and is proportional to that of solar radiation for each site.

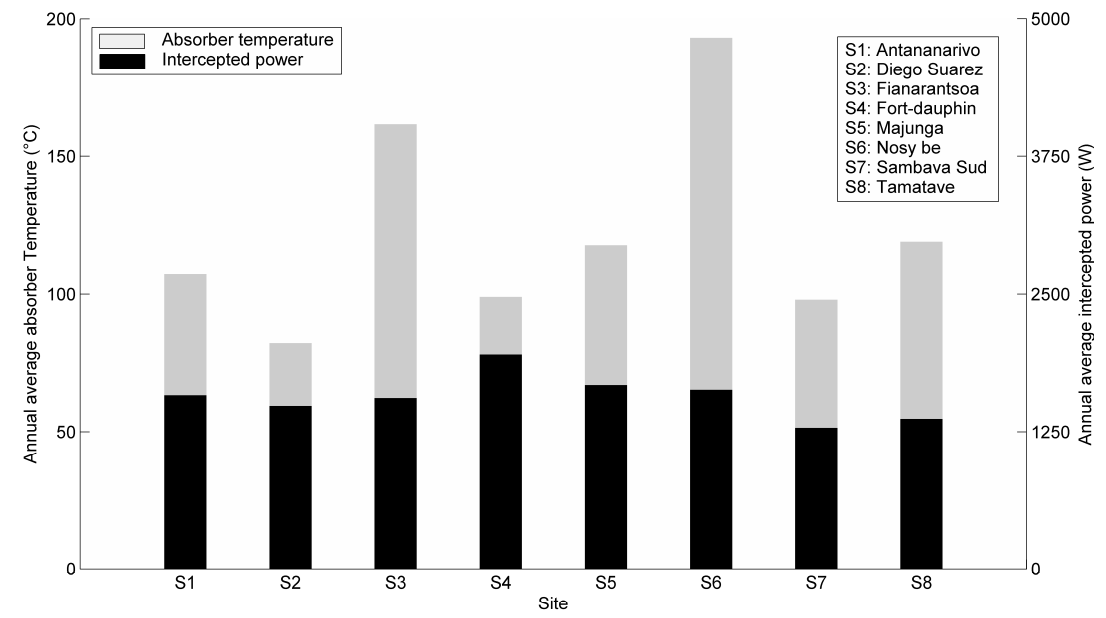

Figure 6. Yearly mean absorber temperature and intercepted power per site. 
Considering the intercepted power by the collector, the heat transfer coefficients that are influenced by wind speed and ambient temperature, and by use of equation (7), the thermal balance equation enables to determine the absorber temperature variation (Figure 6).

It can be seen from Figure 6 that the absorber temperature is not only conditioned by the solar radiation rate received. Indeed, in spite of the highest intercepted power, Fort-dauphin site (S4) does not enable to have the highest average temperature for the absorber while the site of SambavaSud (S7) enables to have nearly the same temperature with the lowest power received.

It is obvious that weather conditions parameters influence and have an impact on the variation of the absorber temperature. Hence, equation (10), in relation with equation (7), relates the convection heat transfer coefficient onto the upper area of the absorber. This coefficient especially depends on wind speed variation of the studied site. Considering three sites, namely Fianarantsoa (S3), Fort-dauphin (S4) and Nosy be (S6), where there are disturbances between intercepted power rate and the absorber temperature, the wind speed variation is established to assess the absorber temperature behaviour (Figure 7).

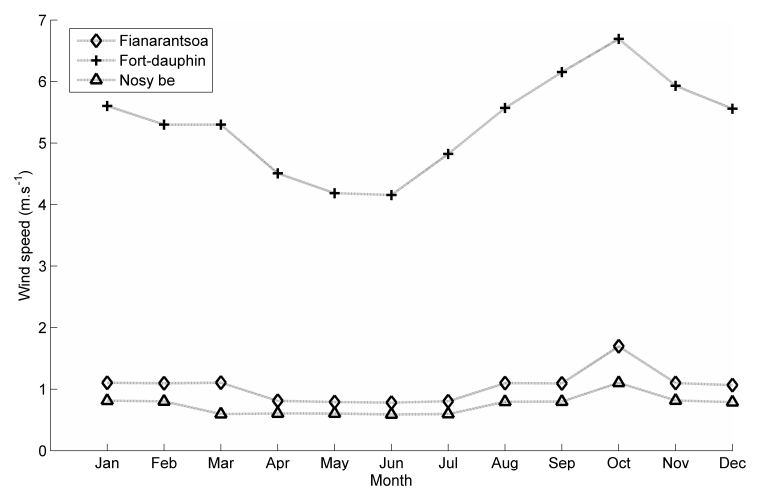

Figure 7. Wind speed variation throughout the selected year.

Figure 7 shows that in spite of a huge solar radiation rate, the site of Fortdauphin is also subjected to a high intensity of wind speed throughout the 
year, between 4 and $6\left(\mathrm{~m}_{\mathrm{s}}{ }^{-1}\right)$. Then this wind condition causes a convection phenomenon on the upper area of the absorber and disturbs the radiative heat transfer between the parabolic collector and the absorber. On the other hand, the two other sites, Fianatantsoa and Nosy be, with a wind speed of less than $1.5\left(\mathrm{~m} . s^{-1}\right)$, are more safeguarded and less exposed to wind. Thereby, the conversion of solar radiation in thermal energy on the absorber is more effective.

According these results, the model simulation effectively shows thermal conversion behaviour of the system collector-absorber and the influence of the weather conditions, the wind speed especially, on this thermal process.

\subsubsection{Thermal energy efficiency of dish Stirling system}

As aforesaid in Subsection 2.2.3, the model used considers that thermal efficiency of the dish Stirling system results from the product of collector and Stirling engine thermal efficiencies defined by equation (11). For the simulation, the working gas used in the Stirling engine is hydrogen. Besides, to be consistent with model simulation, certain system parameters have been fixed and given in Table 1 to simplify the studied model especially the properties of working gas and the engine configurations (volumetric ratio and heat losses).

Table 1. Main parameters for Stirling engine simulation

\begin{tabular}{|c|c|c|}
\hline Description & Symbol & Value \\
\hline Transmittance-absorption product & $\tau \alpha$ & 0.90 \\
\hline Reflectivity of the collector & $\sigma_{r e f}$ & 0.97 \\
\hline Effectiveness of the regenerator & $\varepsilon_{r}$ & 0.90 \\
\hline $\begin{array}{l}\text { Molar specific heat capacity of the working gas } \\
\text { (hydrogen) }\end{array}$ & $c_{V}$ & $8.25\left(\mathrm{~J} \cdot \mathrm{mol}^{-1} \cdot \mathrm{K}^{-1}\right)$ \\
\hline Volumetric ratio in the engine & $\lambda$ & 2 \\
\hline Conduction heat loss coefficient & $k_{0}$ & $2\left(\mathrm{~W} \cdot \mathrm{K}^{-1}\right)$ \\
\hline $\begin{array}{l}\text { Convection heat transfer coefficient on the cold } \\
\text { side heat exchanger }\end{array}$ & $h_{c v, k}$ & $200\left(\mathrm{~W} . \mathrm{K}^{-1}\right)$ \\
\hline
\end{tabular}


Convection heat transfer coefficient on the hot heat exchanger
Radiation heat transfer coefficient

$$
h_{c V, h} \quad 200\left(\mathrm{~W} . \mathrm{K}^{-1}\right)
$$

$$
h_{r d, h} \quad 4 \times 10^{8}\left(\mathrm{~W} . \mathrm{K}^{-4}\right)
$$

This table (Table 1) indicates the main parameters used for the Stirling engine simulation. It should be noted that conduction/convection/radiation heat transfer and heat losses coefficients are estimated from the work that have been already done in this field [15, 17, 18, 20]. Besides, the effectiveness of the regenerator $\varepsilon_{r}$ is supposed to increase the power efficiency of the engine. In other words, this effectiveness value $\left(\varepsilon_{r}=0.90\right)$ represents the power efficiency maximum rate reached by the Stirling engine. The volumetric ratio $(\lambda=2)$ corresponds to the volumes ratio between heating and cooling phases (heating volume is twice that of cooling) during the regenerative processes.

Considering the above mentioned parameters and by use of equations (12) and (15), the thermal efficiencies of the parabolic collector and Stirling engine are obtained per site and given in Figure 8.

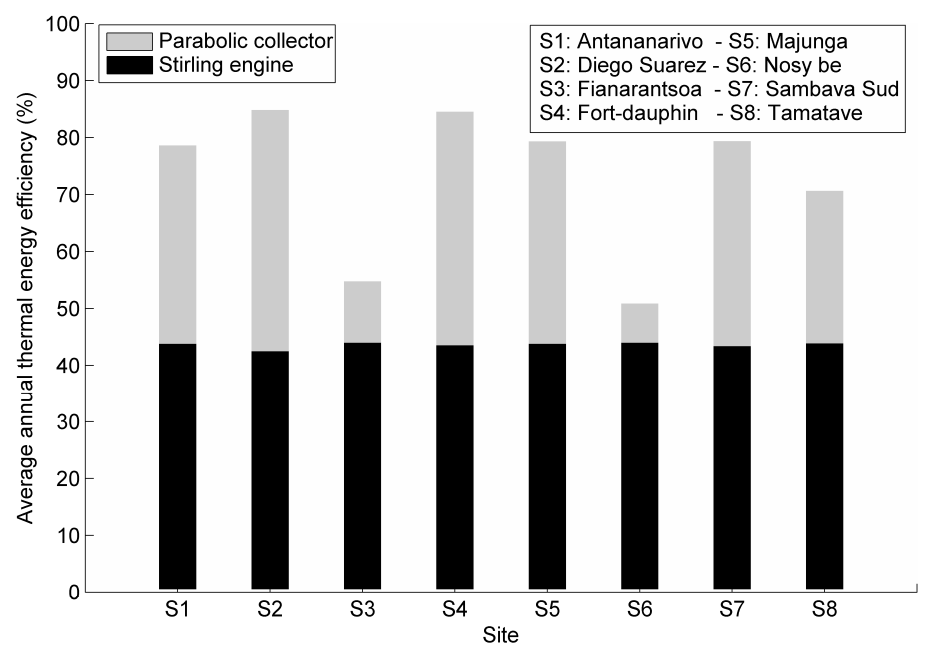

Figure 8. Yearly mean thermal energy efficiencies of the collector and Stirling engine per site. 
As can be seen from Figure 7 and according to the model used, the thermal energy efficiency of the Stirling engine is almost the same value for the eight studied sites between 42 and 45(\%). Furthermore, the thermal energy efficiency of the collector considerably varies for each site between 70 and 85(\%), especially for coastal zones namely in Diego Suarez (S2), Fort-dauphin (S4), Majunga (S5), SambavaSud (S7) and Tamatave (S8), as in the capital city, Antananarivo (S1), that also has a high collector thermal energy efficiency. This trend is reflected on the overall efficiency of the dish Stirling system as presented in Figure 9.

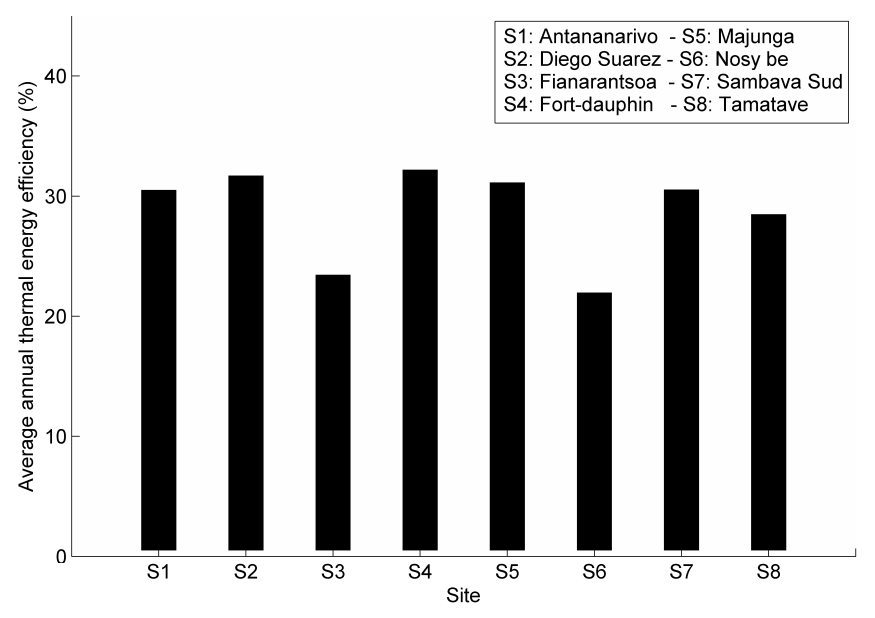

Figure 9. Yearly mean overall thermal efficiency of dish Stirling system.

Results obtained from dish Stirling efficiency simulation of the studied model are shown in Figure 8. Accordingly, the overall thermal efficiency of the system varies between 21.6 and 32.2(\%).

Based on these results and as aforesaid, the coastal zones are more suitable for this type of solar plant especially in the North (Diego Suarez) and the Northwest (Majunga) as well as in the South (Fort-dauphin) of Madagascar, with, respectively, thermal efficiencies of 31.65(\%), 31.07(\%) and 32.17(\%). Both of them are located on the littoral with altitudes below $110(\mathrm{~m})$ and are submitted to a warm climate with high solar radiation rates. Besides, thermal amplitude is very high in these regions between 10 and $40\left({ }^{\circ} \mathrm{C}\right)$ which can promote the system efficiency. 
In the other hand, the sites on the east coast and in the central highlands are less adapted to the system even though the system efficiency in Antananarivo reaches $30.51(\%)$. However, it should be noted that all studied sites present propitious efficiency over 21(\%).

\section{Conclusion}

This paper presents a thermal energy efficiency investigation of dish Stirling system for eight main sites in Madagascar. A theoretical model of dish Stirling based on the geometrical configuration and heat transfer was developed and coded on Matlab 7.10.

While using weather data of the aforementioned sites, it follows from simulation results that the solar radiation varies according to geographic location, that is, Madagascar has various microclimates. Indeed, the model used shows that the system thermal efficiencies according to the studied sites depend on the thermal efficiency rate of the parabolic collector and are influenced by weather conditions on each region of the island. Therefore, the coastal zones are more propitious to the system with an average annual thermal efficiency over 30(\%) especially in the North, in Diego Suarez with 31.65(\%), and in the Northwest, in Majunga 31.07(\%), well as in the South in Fort-dauphin where the thermal efficiency rate is maximal compared to other sites with 32.17(\%).

On the whole, Madagascar has a huge untapped solar potential mainly on coastal zones where power generation is still precarious like in the South with a disadvantaged population, or in the north regions that are heavily dependent on diesel power plants. The establishment of this type of the system (dish Stirling) will give both clean and sustainable energy source to meet population energy needs.

\section{References}

[1] Thomas Mancini, Solar-electric Dish Stirling System Development, 1997.

[2] M. S. Ben Aïssa, M. Ben Jebli and S. Ben Youssef, Output, renewable energy consumption and trade in Africa, Energy Policy 66 (2014), 11-18. 
[3] L. Hammar, J. Ehnberg, A. Mavume, B. C. Cuamba and S. Molander, Renewable ocean energy in the Western Indian Ocean, Renewable and Sustainable Energy Reviews 16(7) (2012), 4938-4950.

[4] Y. S. Mohammed, M. W. Mustafa and N. Bashir, Status of renewable energy consumption and developmental challenges in Sub-Sahara Africa, Renewable and Sustainable Energy Reviews 27 (2013), 453-463.

[5] Robert Stirling, Stirling Air Engine and the Heat Regenerator, Patent No. 4081, 1816.

[6] B. Kongtragool and S. Wongwises, A review of solar-powered Stirling engines and low temperature differential Stirling engines, Renew Sustain Energy Rev. 7(2) (2003), 131-154.

[7] S. Petrescu, M. Costea, C. Harman and T. Florea, Application of the direct method to irreversible Stirling cycles with finite speed, International Journal of Energy Research 26(7) (2002), 589-609.

[8] Y. Cao, Theory and performance analysis of a new heat engine for concentrating solar power, International Journal of Energy Research 38(14) (2014), 1812-1824.

[9] V. Siva Reddy, S. C. Kaushik and S. K. Tyagi, Exergetic analysis and performance evaluation of parabolic dish Stirling engine solar power plant, International Journal of Energy Research 37(11) (2013), 1287-1301.

[10] R. S. Moghadam, H. Sayyaadi and H. Hosseinzade, Sizing a solar dish Stirling micro-CHP system for residential application in diverse climatic conditions based on 3E analysis, Energy Conversion and Management 75 (2013), 348-365.

[11] T. Mancini, P. Heller, B. Butler, B. Osborn, W. Schiel, V. Goldberg, R. Buck, R. Diver, C. Andraka and J. Moreno, Dish-Stirling systems: an overview of development and status, Journal of Solar Energy Engineering 125(2) (2003), 135-151.

[12] Mines and Energy Ministry, WWF, Energy Sector Diagnosis in Madagascar, 2012.

[13] ICSHP-UNIDO, World Small Hydropower Development Report 2013Madagascar, 2013.

[14] Paul Fraser, Stirling Dish System Performance Prediction Model, University of Wisconsinmadison, 2008.

[15] M. Abbas, N. Said and B. Boumeddane, Thermal analysis of Stirling engine solar driven, Revue des Energies Renouvelables 11(4) (2008), 503-514.

[16] S. Y. Wu, L. Xiao, Y. Cao and Y. R. Li, A parabolic dish/AMTEC solar thermal power system and its performance evaluation, Energy 87 (2010), 452-462. 
[17] M. H. Ahmadi, H. Sayyaadi, S. Dehghani and H. Hosseinzade, Designing a solar powered Stirling heat engine based on multiple criteria: maximized thermal efficiency and power, Energy Conversion and Management 75 (2013), 282-291.

[18] Li Yaqi and He Yaling, Wang Weiwei, Optimization of solar-powered Stirling heat engine with finite-time thermodynamics, Renewable Energy 36 (2011), 421-427.

[19] COMESA Secretary, Lusaka, Zambia, Reference Database on Renewable Energy for COMESA Region, 2011.

[20] Iskander Tlili and Sa'ed A. Musmar, Thermodynamic evaluation of a second order simulation for Yoke Ross Stirling engine, Energy Conversion and Management 68 (2013) 149-160. 


\begin{tabular}{|c|c|}
\hline & Proof read by: .......................... \\
\hline Paper No. PPH-1504012-HMT & $\begin{array}{l}\text { Copyright transferred to the Pushpa } \\
\text { Publishing House }\end{array}$ \\
\hline $\begin{array}{l}\text { Kindly return the proof after } \\
\text { correction to: }\end{array}$ & Signature: ....................................... \\
\hline The Publication Manager & Date: .......................................... \\
\hline $\begin{array}{c}\text { Pushpa Publishing House } \\
\text { Vijaya Niwas }\end{array}$ & Tel: .......................... \\
\hline $\begin{array}{c}\text { 198, Mumfordganj } \\
\text { Allahabad-211002 (India) }\end{array}$ & Fax: $\ldots \ldots \ldots \ldots \ldots \ldots \ldots \ldots$ \\
\hline $\begin{array}{l}\text { along with the print charges* } \\
\text { by the fastest mail }\end{array}$ & Number of additional reprints required \\
\hline *Invoice attached & $\begin{array}{l}\text { Cost of a set of } 25 \text { copies of additional } \\
\text { reprints @ Euro } 12.00 \text { per page. } \\
\text { ( } 25 \text { copies of reprints are provided to the } \\
\text { corresponding author ex-gratis) }\end{array}$ \\
\hline
\end{tabular}

